\title{
Ecotoxicity studies of the levulinate ester series
}

\author{
Laura Lomba ${ }^{\mathrm{a}}$, Selene Muñiz ${ }^{\mathrm{b}}, \mathrm{M}^{\mathrm{o}}$ Rosa Pino ${ }^{\mathrm{a}}$, Enrique Navarro ${ }^{\mathrm{b}}$ and Beatriz Giner ${ }^{\mathrm{a}}$ \\ ${ }^{a}$ Facultad de Ciencias de la Salud, Universidad San Jorge, Villanueva de Gállego,
} 50830, Zaragoza, Spain

${ }^{\mathrm{b}}$ Instituto Pirenaico de Ecología (CSIC) Av. Montañana 1005, 50059, Zaragoza, Spain *Corresponding author: Beatriz Giner. E-mail. bginer@usj.es Phone: 34976060100

\begin{abstract}
The increasing interest in the development of novel green solvents has led to the synthesis of benign alternative products with minimized environmental impacts. However, most of published studies on green solvents focus primarily on their physicochemical properties, with limited emphasis on absence of ecotoxicological assessment. In this study, we evaluated the acute ecotoxicity of four levulinates (levulinic acid, methyl levulinate, ethyl levulinate and butyl levulinate) on freshwater algae (Chlamydomonas reinhardtii), bacteria (Vibrio fischeri), daphnids (Daphnia magna) and earthworms (Eisenia foetida) using various dose-response tests. As a general trend, the toxicity of levulinate esters in aquatic exposure (assessed as the $\mathrm{EC}_{50}$ ) increased as a function of increasing alkyl chain length; accordingly, the most toxic compound for the aquatic organisms was butyl levulinate, followed by ethyl levulinate and methyl levulinate. The most toxic compound for Eisenia foetida (terrestrial exposure) was methyl levulinate, followed by ethyl levulinate, butyl levulinate and levulinic acid; in this case, we observed an inverse relationship between toxicity and alkyl chain length. Based on both the lowest $\mathrm{EC}_{50}$ found in the aquatic media and the ratio between predicted environmental concentration (PEC) and the predicted no-effect concentration (PNEC), we have estimated the maximum allowable values in the
\end{abstract}


environment for these chemicals to be $1.093 \mathrm{mg} \mathrm{L}^{-1}$ for levulinic acid, $2.761 \mathrm{mg} \mathrm{L}^{-1}$ for methyl levulinate, $0.982 \mathrm{mg} \mathrm{L}^{-1}$ for ethyl levulinate and $0.151 \mathrm{mg} \mathrm{L}^{-1}$ for butyl levulinate.

Keywords: levulinic acid, methyl levulinate, ethyl levulinate, butyl levulinate, lethal concentration, acute toxicity. 


\section{Introduction}

Green Chemistry is a philosophy aimed at designing alternative products and processes that minimize the use and generation of hazardous substances (Anastas and Warner 1998), creating safer products, reducing waste, eliminating costly end-of-pipe treatments and reducing the use of energy and resources. However, it is difficult to quantify the "greenness" of chemical products or processes although several attempts have been proposed to achieve this goal; Life Cycle Assessment (Wernet et al. 2010) or the Persistence and Spatial Range methods (Scheringer 2002) are examples of this. Nonetheless, it is possible to estimate the environmental "goodness" of a chemical process based on the "Twelve Principles of Green Chemistry" (Anastas and Warner 1998). According to these Principles, solvents should exhibit low vapor pressure, high boiling point, and high biodegradability under environmental conditions; be odorless and easy to recycle after use; and be able to dissolve as many chemical compounds as possible. In addition, green solvents should be non-toxic and non-harmful to the environment and to health, inexpensive and come from renewable resources. (Ahluwalia and Varma 2009).

Although no perfect green solvent exists that could be applied in all situations, several alternatives have recently been developed (i.e., solvents from biomass, ionic liquids, supercritical fluids, etc.) (Diaz-Alvarez et al. 2011). Solvents from biomass can be obtained by enzymatic or esterification and fermentation processes. Among these solvents are levulinic acid and its esters, terpenes, lactates, furfural, glycols, etc (Timokhin et al. 1999).

Concretely, levulinate esters and levulinic acid are used as flavors, in the fragrance industry, in cigarette manufacturing (Keithly et al. 2005) or as substrates for various types of condensation and addition reactions (Khusnutdinov et al. 2007). Although 
some data exist regarding their molecular behavior (Guerrero et al. 2011; Lomba et al. 2013; Lomba et al. 2011), information regarding their toxicity and ecotoxicity is scarce. Several reports deem levulinic acid (LA) to be non-toxic (Tischer et al. 1942). However, we hypothesize that the toxicity of levulinates will increase as a function of the length of the alkyl chain based on toxicity data available for analogous compounds containing alkyl chains with different lengths (Haibo X. 2013; Xiaohua Lu 2009).

We have carried out a detailed study of the environmental toxicity of levulinic acid (LA), methyl levulinate (ML), ethyl levulinate (EL) and butyl levulinate (BL). Three standard ecotoxicological tests were used: the inhibition of bioluminescence of Vibrio fischeri bacteria, the Daphnia magna (freshwater crustacean) acute immobilization test, and the acute toxicity test in Eisenia foetida. In addition, we have evaluated the shortterm toxicity of levulinates to the photosynthesis of Chlamydomonas reinhardtii using fluorimetry. The results were analyzed and related to the physicochemical properties previously reported for these compounds (Guerrero et al. 2011; Lomba et al. 2013). We have also provided the first approaches for risk assessment of these compounds in aquatic and terrestrial environments.

\section{Materials and methods}

\section{Chemicals}

All solvents derived from biomass used in this study were provided by Sigma-Aldrich:

LA, ML and BL with a purity of $98 \%$ and EL with a purity of $99 \%$. These test chemicals were special-grade reagents and used without purification. The chemical structures and molecular weight formula weights of the compounds studied are shown in Fig. 1. Trend analysis and quantitative structure -activity relationship (QSAR) models were applied with the software QSAR Toolbox 2.3 (QSAR Toolbox) which 
helped to determine the levulinate concentrations to be tested. QSAR is based on the correlation between structural characteristics of series of molecules and their biological activity or chemical reactivity. Furthermore, for each of the tests carried out, a previous study was performed to refine the range of concentrations and ensure concentrations within $\mathrm{EC}_{50}$.

Positive and negative controls were used for all the bioassays and the results were acceptable in all the cases according to the criteria established in each of the standardized used method. Details of controls used in each test are provided below.

\section{Assessing the impacts of levulinates on algal photosynthesis}

\section{Culture of Chlamydomonas reinhardtii}

Exponential-phase unicellular green algae (Chlamydomonas reinhardtii $\mathrm{CC} 125)$ were used for the experiments. The algae were grown for 72 hours on an orbital shaker at 90 rpm under a continuous illumination of $130 \mu \mathrm{E} \mathrm{PAR} \cdot \mathrm{m}^{-2} \cdot \mathrm{s}^{-1}$ from four fluorescent tubes (Blau aquaristic T5HO, $39 \mathrm{w} \cdot 10000 \cdot \mathrm{K}^{-1}$ ) in an incubator at $25^{\circ} \mathrm{C}$. The culture medium was "Talaquil", prepared as described in Szivák et al. (Szivak et al. 2009) except that $\mathrm{CuCl}_{2} \cdot 2 \mathrm{H}_{2} \mathrm{O}$ and $\mathrm{ZnCl}_{2}$ were used instead of the corresponding sulfates. Furthermore, the $\mathrm{pH}$ of the culture was adjusted to 7.5 using MOPS.

\section{Exposure to levulinates}

The exposure medium consisted on a MOPS solution $(10 \mathrm{mM})$ with double distilled water (Milli-Q), adjusted to a $\mathrm{pH}$ of 7.5 using $\mathrm{KOH}$. Different concentrations of these chemicals have been tested in order to obtain dose-response curves, with two replicates (flasks) for each one. In case of levulinic acid concentrations ranged between 40-1800

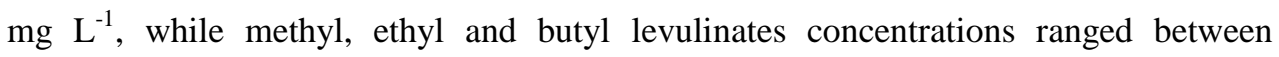


0-33000 $\mathrm{mg} \mathrm{L}^{-1}, 0-22000 \mathrm{mg} \mathrm{L}^{-1}$ and 0-5500 $\mathrm{mg} \mathrm{L}^{-1}$ respectively. Negative controls have been also tested. Dose-response curves have been repeated 3 times. The 72-hour-old algae have been centrifuged (10 min, 3000 r.p.m.) and the concentrate have been used to obtain an optical density $\left(\mathrm{OD}_{685}\right)$ of 0.3 , equivalent to 1150000 cells $\mathrm{mL}^{-1}$.

\section{Measuring of fluorescence parameters}

A Mini-PAM fluorometer (from WALZ, Effeltrich, DE) was used to measure photochemical quantum yield, Y (II), in algal suspensions contained in an optical glass cuvette. Suspensions were maintained under constant agitation using a micro stirrer (Spinette Cel Stirrer from STARNA, Essex, UK). The settings used were as follows: an ML level of $0.15 \mu \mathrm{mol} \mathrm{m} \mathrm{m}^{-2} \mathrm{~s}^{-1}$, SP of $1577 \mu \mathrm{mol} \mathrm{m} \mathrm{m}^{-2}$, and pulses $0.8 \mathrm{~s}$ in duration. Fluorescence parameters were measured on $2 \mathrm{~mL}$ algal suspension after 1 and 2 hours of exposure. After $30 \mathrm{~s}$ of acclimatization to the measuring light conditions $(\approx 50-60$ $\mu \mathrm{mol} \mathrm{m} \mathrm{m}^{-2} \cdot \mathrm{s}^{-1}$ ), between 4 and 5 consecutive $\mathrm{Y}$ (II) measurements were made at 10second intervals.

\section{The Inhibition of Bioluminescence of Vibrio fischeri}

\section{Vibrio fischeri culture}

The lyophilized Vibrio fischeri (strain NRRL-B-11177) used for the bioluminescence inhibition assays were purchased from Macharey-Nagel (ref. 945 006). These experiments were carried out in accordance with the test conditions and the operating protocol of the Vibrio fischeri acute toxicity test (UNE-EN-ISO 11348-3 2007). Prior to testing, bacteria were rehydrated using the corresponding reactivation solution provided by the manufacturer. The reactivated bacteria were stored for $5 \mathrm{~min}$ in the refrigerator at a temperature between $2-8^{\circ} \mathrm{C}$. 


\section{Exposure to levulinates}

Several dilutions for each of the four studied chemicals were prepared using a $2 \% \mathrm{NaCl}$ stock solution. The different concentrations ranges assessed for this bioassay for these compounds were $0-20000 \mathrm{mg} \mathrm{L}^{-1}$ for LA, $0-2000 \mathrm{mg} \mathrm{L}^{-1}$ for ML, 0-900 $\mathrm{m} \mathrm{L}^{-1}$ for EL and 0-500 $\mathrm{m} \mathrm{L}^{-1}$ for BL. Additionally, positive controls with phenol, $42.5 \mathrm{mg} \mathrm{L}^{-1}$ and zinc sulfate, $2.2 \mathrm{mg} \mathrm{L}^{-1}$ and negative controls were tested (Jennings et al. 2001). The $\mathrm{pH}$ of the solutions were adjusted to 7-7.5 using either $0.1 \mathrm{M} \mathrm{NaOH}$ or $0.1 \mathrm{M} \mathrm{HCl}$ solutions.

Next, $0.5 \mathrm{~mL}$ of the reactivated bacterial suspension was transferred to cuvettes. The solution equilibrated for $10 \mathrm{~min}$ at $15^{\circ} \mathrm{C}$, and subsequently, the first measurements were taken to obtain the initial luminescence; then $0.5 \mathrm{~mL}$ of each dilution to be tested was added to the cuvette. The inhibition of luminescence was measured after $30 \mathrm{~min}$. The test was repeated in triplicate.

\section{Measuring the inhibition of bioluminescence}

Luminescence measurements were taken with a Biofix ${ }^{\circledR}$ Lumi-10 luminometer (Macharey-Nagel) using the acute mode (Biotox B) equipped with an ultra-fast singlephoton counter detector covering the $3806-660 \mathrm{~nm}$ spectral range. The toxic effect values reflect the ratio of the decrease in bacterial light production to the remaining light. The sensitivity is 10 fmol ATP when using ATP bioluminescence assays CLS II (Roche Diagnostics GmbH, Mannheim Germany). The ratio between the light intensity lost by the bacterial solution and that remaining after exposure to the toxic sample can be obtained using the following expression:

$$
\Gamma=\frac{\bar{H}_{t}}{100-\bar{H}_{t}}
$$

where $H_{t}$ is the inhibition percent. 
From the results, a linear relationship can be deduced between the function $\Gamma$ and the concentration of the chemicals used, in the following form:

$$
\log \Gamma=\log \mathrm{a}+\log \mathrm{C}
$$

The resulting function was normalized, and the $\mathrm{EC}_{50}$ (chemical concentration resulting in a $50 \%$ reduction of bioluminescence) was calculated.

\section{Daphnia magna Acute Immobilization Test}

\section{Daphnia magna culture}

The Daphnia magna vials used in the acute immobilization assays were purchased from Vidrafoc (ref. DM090812) and were stored at $4^{\circ} \mathrm{C}$. The experiment was carried out in accordance with the OECD 202 test conditions and operating protocol (OC SE TG 202 2004).

First, the medium for the eggs was prepared according to the specifications of the supplier. Next, the eggs were incubated for 72 hours at $20-22{ }^{\circ} \mathrm{C}$ with 6000 lux in a TOXKIT model CH-0120D-AC/DC incubator (supplied by ECOTEST). When a sufficient number of neonates was obtained, a vial of Spirulina was added to feed them 2 hours prior to starting the bioassay.

\section{Exposure to levulinates}

Several dilutions for the four studied chemicals were prepared in aqueous medium solution. In this case, the different concentrations range for these compounds have been between $2200-10000 \mathrm{mg} \mathrm{L}^{-1}$ for LA, 2000-4500 mg L ${ }^{-1}$ for ML, 400-1800 $\mathrm{m} \mathrm{L}^{-1}$ for EL and 0-360 mg L $\mathrm{m}^{-1}$ for BL. Additionally, negative and positive controls with $\mathrm{K}_{2} \mathrm{Cr}_{2} \mathrm{O}_{7}$ (0.6-2.1 $\mathrm{mg} \mathrm{L}^{-1}$ ) were also tested. (OECD 202 1984) Furthermore, the $\mathrm{pH}$ of the solutions was adjusted to be between 7-7.5 using $0.1 \mathrm{M} \mathrm{NaOH}$ or $0.1 \mathrm{M} \mathrm{HCl}$ solutions. 
After 2 hours of feeding, a total of 20 organisms (aged $<24 \mathrm{~h}$ ) were used. The organisms were divided into four groups of five organisms per group. All concentrations with the daphnids were incubated in complete darkness for 24 hours at $20-22^{\circ} \mathrm{C}$. The test was repeated in triplicate.

\section{Measuring of acute immobilization}

After 24 hours in darkness, the immobilization of the daphnids was measured. The daphnids that were unable to swim for 15 seconds after gentle stirring were considered immobile. The probit method (Bliss 1934) was used to calculate the $50 \%$ effect concentration $\left(\mathrm{EC}_{50}\right)$.

\section{Earthworm, acute toxicity test}

\section{Eisenia foetida culture}

Adult Eisenia foetida earthworms (2 months old with clitellum) with individual weights in the range of $300 \mathrm{mg}$ to $600 \mathrm{mg}$ were used in accordance with the test conditions and the operating protocol of the Guidelines for the testing of chemicals. (OECD 207 1984)

\section{Exposure to levulinates}

The artificial soil was composed of $10 \%$ sphagnum peat, $20 \%$ kaolin clay and $70 \%$ industrial fine sand by dry weight. Sphagnum peat was purchased from Verdecora vivarium (Spain) whereas kaolin and industrial sand were obtained from Imerys Ceramics España, S.A. The water content of the mixture was determined by taking an initial sample weight, drying it to a constant mass at $105^{\circ} \mathrm{C}$ for 24 hours, and taking a subsequent measurement. Deionized water was added to adjust the overall moisture content to approximately $35 \%$ of the dry weight, and the medium was thoroughly mixed. The $\mathrm{pH}$ measurements were taken with a Crison Basic $20 \mathrm{pH}$ meter using a $1 \mathrm{M}$ $\mathrm{KCl}$ solution. 
A total of $0.5 \mathrm{~kg}$ of dry artificial soil was placed in a $500 \mathrm{~mL}$ plastic jar, and 10 adult earthworms were added to each jar. Additionally, we prepared several test concentrations in a geometric series and both negative and positive controls (chloracetamide; $24 \mathrm{mg} \mathrm{kg}^{-1}$ ) (OECD 207 1984). The different concentrations prepared for each compound were 1900-6900 $\mathrm{mg} \mathrm{kg}^{-1}$ for LA; 400-900 $\mathrm{mg} \mathrm{kg}^{-1}$ for ML 400-1600 $\mathrm{mg} \mathrm{kg}^{-1}$ for EL and $1400-2500 \mathrm{mg} \mathrm{kg}^{-1}$ for BL. Three jars, each containing 10 adult earthworms, were used for each concentration.

The jars were loosely covered with a film and some air-exchange holes were made. These jars were stored at $20-22^{\circ} \mathrm{C}$ with $80-85 \%$ relative humidity under $400-800$ lux of constant light. Mortality was assessed at 7 and 14 days after treatment. During the bioassay, all organisms were fed with a flavor/water mixture. The test was repeated in triplicate.

Measuring of death of earthworms

After 14 days, the number of dead earthworms was measured. All organisms that were immobile upon digital stimulation were characterized as dead. The probit method (Bliss 1934) was used to calculate the $50 \%$ effect concentration $\left(\mathrm{EC}_{50}\right)$.

\section{Statistics and graphical representation}

Dose-response curves for algal photosynthesis were fitted to a four-parameter logistic curve using $\mathrm{R}$ and the $d r c$ package to obtain the corresponding $\mathrm{EC}_{50}$ values and standard errors (SE). The same package was also used to perform comparison tests, using the $\mathrm{R}$ "compPAR" function; the null hypothesis was that the ratio equals 1 . The ratio was obtained by dividing $\mathrm{EC}_{50}$ values; if it significantly differed from 1 (i.e., $\mathrm{p}<0.05$ ), the null hypothesis was to be rejected. All statistical analysis for daphnids, earthworms and 
bacteria was performed using the SPSS 18.00 software (IBM® SPSS software), in which a threshold of $\mathrm{p}=0.05$ has been set to accept or reject the null hypothesis

\section{Results and discussion}

We found that all of the levulinates studied were toxic to the test organisms in a concentration-dependent manner. Similarly, in agreement with our hypothesis, the aquatic toxicity of levulinate series increased as a function of the alkyl chain length; accordingly the toxicity of the series of compounds for the aquatic organisms was BL, followed by EL and ML. LA was the most toxic compound in the freshwater algae assay (see Tab. 1), that was due to its high acidity (buffer capacity of MOPS was surpassed). In terrestrial exposure (tests with Esenia foetida), the most toxic compound was ML followed by EL, BL and LA; in this case, the toxicity of levulinates decreased as the length of alkyl chain increased (Tab. 1).

\section{Levulinate toxicity in algae}

The toxicity followed the trend of $\mathrm{BL}, \mathrm{EL}$ and $\mathrm{ML}$ (the values of $\mathrm{EC}_{50}$ decreased as the length of alkyl chain in the levulinate series increased (Fig. 2). All values were significantly different. The toxicity, measured as the decrease of in the yield of Photosystem II, Y (II), indicates that levulinates affect the electron flow. This effect is commonly induced by a wide range of chemicals such as $\mathrm{Zn}$ (Corcoll 2011, Corcoll et al. 2011), $\mathrm{Hg}$ (Juneau et al. 2001) and $\mathrm{Cu}$ (Juneau et al. 2002), volatile compounds (Brack et al. 1998), herbicides (Brack and Frank 1998, Conrad et al. 1993, Dorigo and Leboulanger 2001) and ultraviolet radiation (UVR) (Navarro et al. 2008). Even if the underlying processes explaining the levulinate toxicity are unknown, the behavior of minimal fluorescence (F) after 2 hours of exposure (data not shown) seems to point to 
an attenuation of photosynthetic pigments, and particularly a decrease in chlorophyll $a$. The value of $\mathrm{F}$ was related to the stability of the light-harvesting complexes and thus to the stability of its pigments (Yamada et al. 1996). Moreover, LA has been described as an inhibitor of chlorophyll synthesis in algae and higher plants (Johanningmeier and Howell 1984). Another possible explanation may be linked to the loss of integrity of the photosynthetic membranes (Brack et al. 1998); the hydrophobicity of the levulinates would facilitate their interaction with lipid membranes (Lomize et al. 2007). The subsequent disruption of the photosynthetic electron chain might also lead to ROS production (Stoiber et al. 2011), increasing the oxidative stress (Guasch and Sabater 1998) and the concomitant toxic effects on the photosynthetic yield.

\section{Levulinate toxicity in bacteria}

The most toxic compounds as measured using the bioluminescence assay followed the decreasing ranked order series of BL followed by EL, ML and LA. All values were significantly different from each other and followed trends similar to those of the algae study, i.e., the values of $\mathrm{EC}_{50}$ decrease as the length of the alkyl chain increases (Fig. 3). Bacterial bioluminescence reactions are coupled to the electron transport system in cellular respiration and are indicative of cellular metabolism; i.e., lower bioluminescence implies decreased cellular respiration. Moreover, the addition of a variety of chemicals are known to affect the cellular respiration by the modification of both protein and lipid biosynthetic pathways, altering the luminescence emission; i.e., in the presence of pollutants, the natural bioluminescence of Vibrio fischeri decreases (Onorati and Mecozzi 2004). 


\section{Levulinate toxicity in daphnids}

Results obtained in the Daphnia magna bioassay are shown in Fig. 4. The toxicity rank of the levulinate series decreases as follows: BL followed by EL, ML and LA. Additionally, the trend observed for Daphnia magna is the same as the rest of the aquatic bioassays tested; for levulinate esters, the values of $\mathrm{EC}_{50}$ decreases as the length of alkyl chain increases.

The different toxicity of the studied chemicals can be due to the structural variability. We hypothesize that if the toxicants are absorbed by daphnids, the more hydrophobic compounds have a greater potential to cross the plasma membrane, thus eliciting greater ecotoxicity.

\section{Levulinate toxicity in earthworms}

Although the previous studies we performed show a direct relationship between toxicity and alkyl chain length, our results show opposite trends between aquatic and terrestrial compartments. In the Eisenia foetida, the toxicity of the series follows the rank order of ML followed by $\mathrm{EL}, \mathrm{BL}$ and $\mathrm{LA}$; i.e., for levulinate esters, the values of $\mathrm{EC}_{50}$ increase with the length of the alkyl chain (Fig. 5). There are no studies focusing on levulinate toxicity in earthworms; however, there is a report by Roberts and Dorough in which several other chemicals were analyzed and classified according to their toxicity to $E$. foetida (Roberts and Dorough 1984). Interestingly, this study also revealed that Eisenia was unexpectedly tolerant to many solvents and fuels, even at very high concentrations (i.e., cyclohexane, dichloromethane or methanol). However, other solvents such as acetone or benzene were moderately toxic while benzaldehyde and dimethylacetamide were very toxic (Roberts and Dorough 1984). 
According to the classification presented in this study, LA and BL can be considered as non-toxic, while ML is moderately toxic (Roberts and Dorough 1984).

Considering the differences in toxicity shown by very similar compounds it is difficult for us to correlate the structure and properties of the chemicals tested (i.e., the levulinate series) and their effect in Eisenia. Typically, chemicals that are extremely toxic in mammals are found to be the same in both fish and earthworms. However, some fungicides are known to show the opposite trend (non-toxic for mammals and extremely toxic to fish and earthworms). Many other examples exist that demonstrate little to no correlation between non-target species, and consequently, interspecies extrapolations of chemical hazard from one animal species to another based on toxicity data are not easy to make (Roberts and Dorough 1984). We find that the mechanisms of action for levulinate toxicity are both exposure- and species- dependent.

\section{Environmental Risk Assessment for levulinates}

\section{Physico-chemical properties of levulinates related to toxicity}

$\log P$ can be used to estimate the lipophilicity of molecules, which is related to their ability to cross through biological membranes and influences their fate after uptake. In a previous paper (Lomba et al. 2013; Lomba et al. 2011) values of the logarithm of 1-octanol/water partition coefficient, $\log P$, were computed in silico using the ALOGP method (Ghose and Crippen 1986; Ghose et al. 1988; Viswanadhan et al. 1989) with values of -0.14 for LA, -0.17 for ML, 0.38 for EL and 1.36 for BL. We have compared the computed $\log P$ values to those predicted with the KowWin method (available on http://esc.syrres.com/esc/est_kowdemo.htm) (Meylan and Howard 1995). Using this second approach, the predicted $\log P$ values for the levulinate series are -0.49 for LA 
(empirical value), -0.13 for ML (empirical value), 0.29 for EL and 1.27 for BL. The values obtained from two different methods are different; nonetheless values obtained from KowWin method have been used to correlate our $\log \mathrm{EC}_{50}$ values against the predicted $\log P$ values as shown in Fig. 6.

The levulinate series elicited a direct relationship between the hydrophobicity and ecotoxicity; i.e., the less hydrophilic the chemicals had lower $\mathrm{EC}_{50}$ values in aquatic exposure. The exceptions included LA, which has the lowest $\mathrm{EC}_{50}$ values compared to its $\log P$ in the case of Chlamydomonas reinhardtii $\left(\mathrm{EC}_{50}\right.$ values lower than expected), and $\mathrm{BL}$, which exhibits higher $\mathrm{EC}_{50}$ values in the case of the Vibrio fischeri assay.

Differently from water exposure, it is important to note that there is no direct relationship between the toxicity in soil and the $\log P$. This lack may exist because the partition coefficient is a specific parameter between water and octanol and does not take into account other factors governing the mobility of the pollutants in soils (i.e. cation exchange, chemical solubility equilibrium, biochemical reactions and sorption to soil organic matter).

\section{Environmental toxicity}

Publications related to the environmental toxicity of levulinates are scarce. Only LA has been found to inhibit microorganism growth and ethanol production during fermentation (Almeida et al. 2007). Similarly, Tischer et al. tested LA on rats, guinea pigs, chicks and human beings and stated its innocuousness (Tischer et al. 1942). The aquatic US-EPA ECOTOX database provides a $\mathrm{LC}_{50}$ lethal value of $10 \mathrm{mg} \mathrm{L}^{-1}$ during $24 \mathrm{~h}$ for three different fish species (MacPhee and Ruelle 1969). On the other hand, there are a few predicted aquatic $\mathrm{LC}_{50}$ and $\mathrm{EC}_{50}$ values for our series 
(http://webnet.oecd.org/CCRWEB/Search.aspx) (OECD 2006) which are presented in Table 2.

Several $\mathrm{EC}_{50}$ values from our bioindicator assays were used as a basis for comparing our studied "green solvents" with traditional solvents; for instance, some traditional solvents, such as dimethylformamide or 2-propanol, have been tested in Selenastrum capricornutum with $\mathrm{EC}_{50}$ values of $1714 \mathrm{mg} \mathrm{L}^{-1}$ and $11.719 \mathrm{mg} \mathrm{L}^{-1}$, respectively. (Cho et al. 2008) The algae assays for the levulinate series show lower values than 2propanolol, with the exception of ML. However, all the studied chemicals show higher $\mathrm{EC}_{50}$ values than dimethylformamide except for LA.

For the Vibrio fischeri assay, the $\mathrm{EC}_{50}$ values of three levulinate esters $(\mathrm{ML}, \mathrm{EL}$ and BL) are similar to the values of solvents classified as toxic for the environment, such as benzene with $435 \mathrm{mg} \mathrm{L}^{-1}$ or chloroform with $632 \mathrm{mg} \mathrm{L}^{-1}$; however, LA can be considered as nontoxic for the environment, similarly to acetone with $\mathrm{EC}_{50}=19900 \mathrm{mg} \mathrm{L}^{-1}$, ethanol with $\mathrm{EC}_{50}=45700 \mathrm{mg} \mathrm{L}^{-1}$ or 2-propanol with $\mathrm{EC}_{50}=28100$ $\mathrm{mg} \mathrm{L}^{-1}$ (Jennings et al. 2001).

Comparison of the levulinate series to other solvents based on the Daphnia magna assay revealed that the $\mathrm{EC}_{50}$ values for LA and $\mathrm{ML}$ are similar to those of traditional solvents such as acetone with $7600 \mathrm{mg} \mathrm{L}^{-1}$ (Pawlisz and Peters 1995), ethanol with $12340 \mathrm{mg} \mathrm{L}^{-1}$ or dimethylformamide with $14500 \mathrm{mg} \mathrm{L}^{-1}$ (Hutchinson et al. 2006) which are all considered non-toxic. 


\section{Environmental Risk of levulinates}

The general estimation of environmental risk makes use of the ratio between predicted environmental concentration (PEC) and the predicted no-effect concentration (PNEC). Compounds presenting PEC/PNEC ratios lower than 1 are considered to be substances of low environmental risk. Here, PNECs have been calculated from a dataset which includes both our experimental data (table 1) and previous predicted information (table 2). We selected the most sensitive ecotoxicity experimental value in aquatic bioindicators required from the REACH directive (algae, daphnids and fish) (COM (2003) 644 final29.10.2003. Euroepan Comission). For this reason, we did not take into account bacteria, earthworms and fish results. Therefore, the $\mathrm{EC}_{50}$ of Daphnia magna has been used for the levulinate esters, while for LA, the $\mathrm{EC}_{50}$ of Chlamydomonas reinhardtii was used. According to the REACH directives a factor of 1000 was applied to the $\mathrm{EC}_{50}$ values. The values for PEC that would result in a PEC/PNEC ratio equal or lower than 1 would be1.093 $\mathrm{mg} \mathrm{L}^{-1}$ for LA, $2.761 \mathrm{mg} \mathrm{L}^{-1}$ for ML, $0.982 \mathrm{mg} \mathrm{L}^{-1}$ for EL and $0.151 \mathrm{mg} \mathrm{L}^{-1}$ for BL.

\section{Acknowledgments}

We would like to thank Imerys Ceramics España, S.A. for providing artificial soil for the earthworm tests. The researchers L.Lomba, B.Giner and $\mathrm{M}^{\mathrm{a}}$.R. Pino are supported by the regional Aragon Government (Consolidated Applied Research Group ref. E02) and European Social Fund "Construyendo Europa desde Aragón". The work of S. Muñiz and E. Navarro is supported by the Spanish Ministry of Economy and Competitiveness (National Research Plan, ref. BFU2010-22053) and by the regional Aragon Government (Consolidated Applied Research Group ref. E61). Furthermore, Green Pharmacy acknowledges financial support from EEE53 SL. Business groups: 
Pinares de Venecia División Energética and Brial (ENATICA). Finally, we want to thank Dr. Manuel Gómez (Universidad San Jorge) both for his kind help and for having provided us with useful information. 
References

Ahluwalia VK, Varma RS (2009) Green solvents for organic synthesis. Alpha Science International Ltd., Oxford, U.K.

Almeida JRM, Modig T, Petersson A, Hahn-Hagerdal B, Liden G, Gorwa-Grauslund MF (2007) Increased tolerance and conversion of inhibitors in lignocellulosic hydrolysates by Saccharomyces cerevisiae. Journal of Chemical Technology and Biotechnology 82:340-349.

Anastas PT, Warner JC (1998) Green chemistry: theory and practice. Oxford University Press, Oxford [England]; New York

Bliss CI (1934) The method of probits. Science 79:38-39

Brack W, Frank H (1998) Chlorophyll a fluorescence: A tool for the investigation of toxic effects in the photosynthetic apparatus. Ecotoxicol Environ Saf 40:34-41

Brack W, Rottler H, Frank H (1998) Volatile fractions of landfill leachates and their effect on Chlamydomonas reinhardtii: In vivo chlorophyll A fluorescence. Environmental Toxicology and Chemistry 17:1982-1991

Cho C, Jeon Y, Pham TPT, Vijayaraghavan K, Yun Y (2008) The ecotoxicity of ionic liquids and traditional organic solvents on microalga Selenastrum capricornutum. Ecotoxicol Environ Saf 71:166-171

COM (2003) 644 final de 29.10.2003. Comisión de las comunidades europeas (2003) Propuesta del Reglamento relativa al registro, la evaluación, la autorización y la restricción de las sustancias y los preparados químicos (REACH) por el que se crea la Agencia Europea de Sustancias y Preparados Químicos. CEE Bruselas

Conrad R, Buchel C, Wilhelm C, Arsalane W, Berkaloff C, Duval J (1993) Changes in Yield in In-Vivo Fluorescence of Chlorophyll a as a Tool for Selective Herbicide Monitoring. J Appl Phycol 5:505-516

Corcoll N (2011) The use of pulse amplitude modulated fluorescence techniques for metal toxicity assessment in fluvial biofilms. Dissertation. University of Girona (Spain)

Corcoll N, Bonet B, Leira M, Guasch H (2011) Chl-a fluorescence parameters as biomarkers of metal toxicity in fluvial biofilms: an experimental study. Hydrobiologia 673:119-136

Diaz-Alvarez AE, Francos J, Lastra-Barreira B, Crochet P, Cadierno V (2011) Glycerol and derived solvents: new sustainable reaction media for organic synthesis. Chemical Communications 47:6208-6227

Dorigo U, Leboulanger C (2001) A pulse-amplitude modulated fluorescence-based method for assessing the effects of photosystem II herbicides on freshwater periphyton. J Appl Phycol 13:509-515 
Ghose A, Pritchett A, Crippen G (1988) Atomic Physicochemical Parameters for 3Dimensional Structure Directed Quantitative Structure-Activity-Relationships .3. Modeling Hydrophobic Interactions. Journal of Computational Chemistry 9:80-90

Ghose A, Crippen G (1986) Atomic Physicochemical Parameters for 3-Dimensional Structure-Directed Quantitative Structure-Activity-Relationships .1. PartitionCoefficients as a Measure of Hydrophobicity. Journal of Computational Chemistry $7: 565-577$

Guasch H, Sabater S (1998) Light history influences the sensitivity to atrazine in periphytic algae. J Phycol 34:233-241

Guerrero H, Lafuente C, Royo F, Lomba L, Giner B (2011) P rho T Behavior of Several Chemicals from Biomass. Energy Fuels 25:3009-3013

Haibo X. (2013) Toxicity and Ecotoxicity of Ionic Liquids for Biorefinery . In: Nicholas Gathergood (ed) The Role of Green Chemistry in Biomass Processing and Conversion. Hoboken, Wiley, pp 109-115

Hutchinson T, Shillabeer N, Winter M, Pickford D (2006) Acute and chronic effects of carrier solvents in aquatic organisms: A critical review. Aquatic Toxicology 76:69-92

Jennings V, Rayner-Brandes M, Bird D (2001) Assessing chemical toxicity with the bioluminescent photobacterium (Vibrio fischeri): A comparison of three commercial systems. Water Res 35:3448-3456

Johanningmeier U, Howell S (1984) Regulation of Light-Harvesting ChlorophyllBinding Protein Messenger-Rna Accumulation in Chlamydomonas-Reinhardi - Possible Involvement of Chlorophyll Synthesis Precursors. J Biol Chem 259:3541-3549

Juneau P, El Berdey A, Popovic R (2002) PAM fluorometry in the determination of the sensitivity of Chlorella vulgaris, Selenastrum capricornutum, and Chlamydomonas reinhardtii to copper. Arch Environ Contam Toxicol 42:155-164

Juneau P, Dewez D, Matsui S, Kim S, Popovic R (2001) Evaluation of different algal species sensitivity to mercury and metolachlor by PAM-fluorometry. Chemosphere 45:589-598

Keithly L, Wayne G, Cullen D, Connolly G (2005) Industry research on the use and effects of levulinic acid: A case study in cigarette additives. Nicotine Tobacco Res $7: 761-771$

Khusnutdinov RI, Baiguzina AR, Smirnov AA, Mukminov RR, Whemilev UM (2007) Furfuryl alcohol in synthesis of levulinic acid esters and difurylmethane with Fe and $\mathrm{Rh}$ complexes. Russian Journal of Applied Chemistry 80:1687-1690

Lomba L, Lafuente C, García-Mardones M, Gascón, I., Giner, B. (2013) Thermophysical study of methyl levulinate. J Chem Thermodynamics 65 (2013) 34-41 $65: 34$ 
Lomba L, Giner B, Bandres I, Lafuente C, Pino M.R (2011) Physicochemical properties of green solvents derived from biomass. Green Chem 13:2062-2070

Lomize, Andrei L, Pogozheva, Irina D, Lomize, Mikhail A, Mosberg,Henry I, (2007) The role of hydrophobic interactions in positioning of peripheral proteins in membranes. BMC Struct Biol BMC Structural Biology 7

MacPhee C, Ruelle R (1969) Lethal effects of 1888 chemicals upon four species of fish from western North America. University of Idaho [Forest, Wildlife, and Range Experiment Station], Moscow

Meylan W, Howard P (1995) Atom Fragment Contribution Method for Estimating Octanol-Water Partition-Coefficients. J Pharm Sci 84:83-92

Navarro E, Robinson CT, Behra R (2008) Increased tolerance to ultraviolet radiation (UVR) and cotolerance to cadmium in UVR-acclimatized freshwater periphyton. Limnol Oceanogr 53:1149-1158

OC SE TG 2022004 OC SE TG 2022004 (European C 2 method as described in the EU Regulation 440/2008)

OECD (2006) Ecological Categorization Results from the Canadian Domestic Substance List.

OECD 202 (1984) Guideline for Testing of Chemicals No. 202, Daphnia sp., Acute Immobilisation Test and reproduction Test. OECD, 202, Paris, France 202

OECD 207 (1984) Guideline for Testing of Chemicals No. 207, Earthworm Acute. Toxicity. OECD 207, Paris, France 207

Onorati F, Mecozzi M (2004) Effects of two diluents in the Microtox (R) toxicity bioassay with marine sediments. Chemosphere 54:679-687

Pawlisz A, Peters R (1995) Effects of Sublethal Exposure on Lethal Body Burdens of Narcotic Organic-Chemicals in Daphnia-Magna. Environ Sci Technol 29:613-621

QSAR Toolbox (2009) The OECD QSAR Toolbox for Grouping Chemicals into Categories. In: www.qsartoolbox.org/download.html

Roberts B, Dorough H (1984) Relative Toxicities of Chemicals to the Earthworm Eisenia-Foetida. Environmental Toxicology and Chemistry 3:67-78

Scheringer M (2002) Persistence and spatial range of environmental chemicals : new ethical and scientific concepts for risk assessment. Wiley-VCH, Weinheim

Stoiber TL, Shafer MM, Armstrong DE (2011) Induction of reactive oxygen species in Chlamydomonas reinhardtii in response to contrasting trace metal exposures. Environ Toxicol:n/a-n/a 
Szivak I, Behra R, Sigg L (2009) Metal-Induced Reactive Oxygen Species Production in Chlamydomonas Reinhardtii (Chlorophyceae). J Phycol 45:427-435

Timokhin BV, Baransky VA, Eliseeva GD (1999) Levulinic acid in organic synthesis. Usp Khim 68:80-93

Tischer et al. (1942) The non-toxicity of levulinic acid. J Am Phar Assoc 31(7):217220

UNE-EN-ISO 11348-3 (2007) Water quality - Determination of the inhibitory effect of water samples on the light emission of Vibrio fischeri (Luminescent bacteria test). UNE-EN-ISO 11348-3

Viswanadhan V, Ghose A, Revankar G, Robins R (1989) Atomic Physicochemical Parameters for 3 Dimensional Structure Directed Quantitative Structure - Activity Relationships .4. Additional Parameters for Hydrophobic and Dispersive Interactions and their Application for an Automated Superposition of Certain Naturally-Occurring Nucleoside Antibiotics. J Chem Inf Comput Sci 29:163-172

Wernet G, Conradt S, Isenring HP, Jimenez-Gonzalez C, Hungerbuehler K (2010) Life cycle assessment of fine chemical production: a case study of pharmaceutical synthesis. International Journal of Life Cycle Assessment 15:294-303

Xiaohua Lu YH (2009) Evaluations and Toxicity of ILs. In: D.M.P. Mingos (ed) Toxicity Molecular Thermodynamics of Complex Systems. Springer-Verlag Berlin Heidelberg, pp 179-182

Yamada M, Hidaka T, Fukamachi H (1996) Heat tolerance in leaves of tropical fruit crops as measured by chlorophyll fluorescence. Scientia Horticulturae 67:39-48 


\section{Table 1.}

Effective concentration $\mathrm{EC}_{50}$ for levulinate family compounds

\begin{tabular}{lccccc}
\hline & \multicolumn{2}{c}{ Chlamydomonas reinhardtii } & Vibrio fischeri & Daphnia magna & Eisenia foetida \\
& \multicolumn{2}{c}{$\mathrm{mg} \mathrm{L}^{-1}$} & $\mathrm{mg} \mathrm{L}^{-1}$ & $\mathrm{mg} \mathrm{L}^{-1}$ & $\mathrm{mg} \mathrm{kg}^{-1}$ \\
\cline { 2 - 6 } & $\mathrm{EC}_{50} l \mathrm{~h}$ & $\mathrm{EC}_{50} 2 \mathrm{~h}$ & & \\
\cline { 2 - 6 } Levulinic acid & $1092.5 \pm 26.7$ & $1098.1 \pm 13.7$ & $5687 \pm 1325$ & $6234 \pm 466$ & $3615 \pm 68$ \\
Methyl levulinate & $20720.9 \pm 1083.6$ & $18655.8 \pm 986.1$ & $883 \pm 5$ & $2761 \pm 512$ & $620 \pm 14$ \\
Ethyl levulinate & $6889.0 \pm 405.3$ & $6065.9 \pm 757.8$ & $182 \pm 5$ & $982 \pm 66$ & $848 \pm 24$ \\
Butyl levulinate & $2151.8 \pm 190.1$ & $1640.0 \pm 127.0$ & $83 \pm 3$ & $151 \pm 13$ & $1899 \pm 154$ \\
\hline
\end{tabular}




\section{Table 2.}

Predicted concentration in $\mathrm{mg} \mathrm{L}^{-1}$ for levulinate family compounds. (OECD 2006)

\begin{tabular}{lcccc}
\hline & Levulinic acid & Methyl levulinate & Ethyl levulinate & Butyl levulinate \\
\cline { 2 - 5 } & & & & 117.3 \\
Feather minnow $\left(\mathrm{LC}_{50}\right)$ as predicted by Topkat v6.1 & 1500 & 352 & 179369 & 64069 \\
Fish $\left(\mathrm{LC}_{50}\right)$ as predicted by Ecosar v0.99g & 189000 & 296092 & 180.2 & 38 \\
Fish $\left(\mathrm{LC}_{50}\right)$ as predicted by Aster & 13613 & 387.3 & & \\
Daphnia $\left(\mathrm{EC}_{50}\right)$ as predicted by Topkat v6.1 & 330.3 & & & \\
\hline
\end{tabular}


<smiles>CC(=O)CCC(=O)O</smiles>

Levulinic acid<smiles>CCOC(=O)CCC(C)=O</smiles>

Ethyl levulinate<smiles>COC(=O)CCC(C)=O</smiles>

Methyl levulinate<smiles>CCCCOC(=O)CCC(C)=O</smiles>

Butyl levulinate

Fig.1. Chemical structures of the compounds studied 


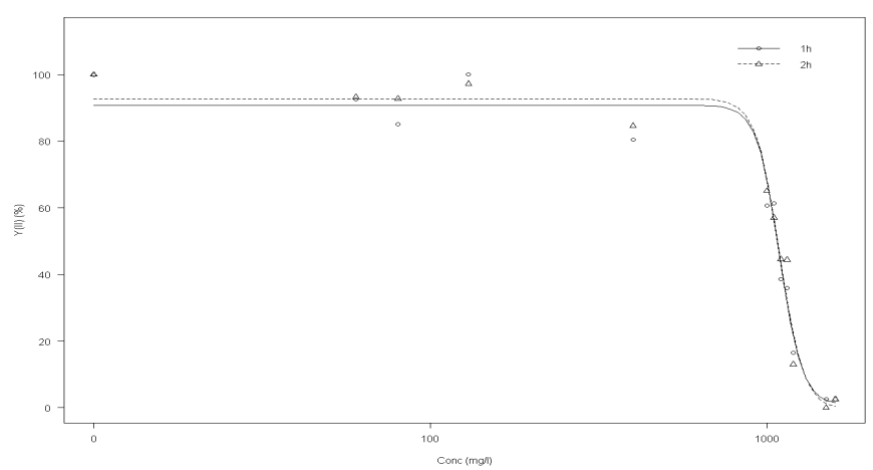

Levulinic acid

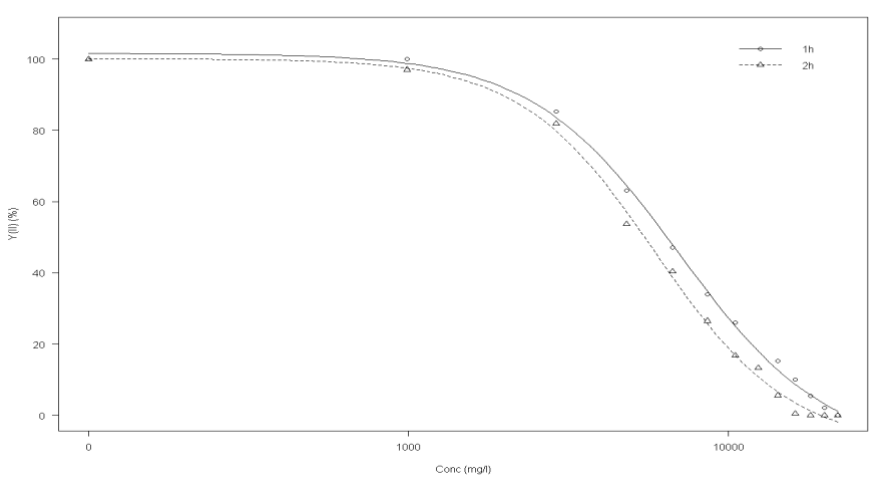

Ethyl levulinate

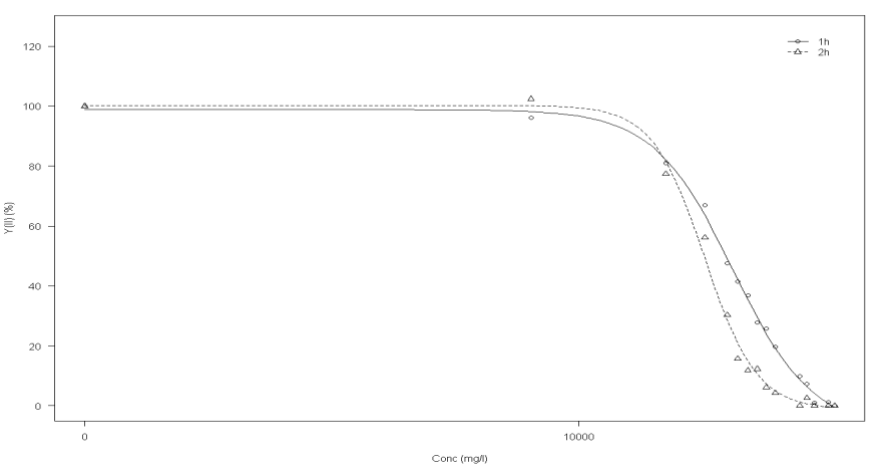

Methyl levulinate

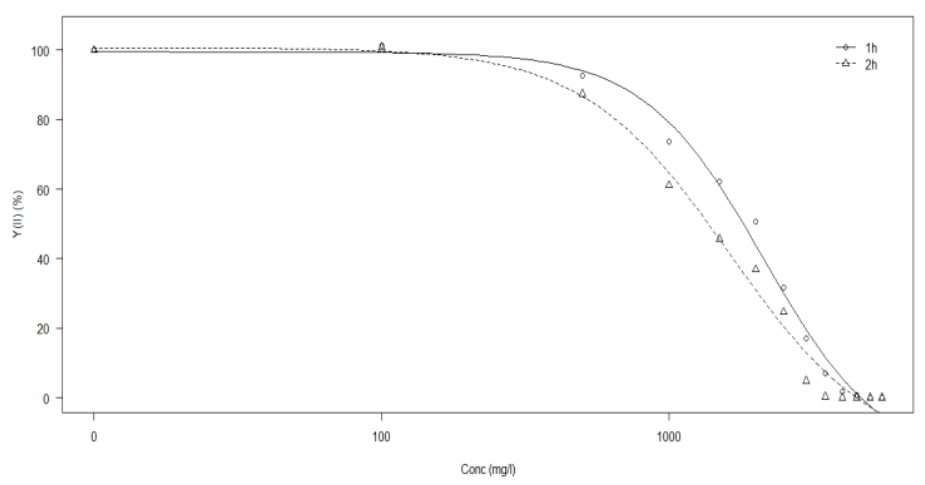

Butyl levulinate

Fig.2. Dose- response curves after 1 and $2 \mathrm{~h}$ of exposure for compounds studied for Chlamydomonas reinhardtii. 


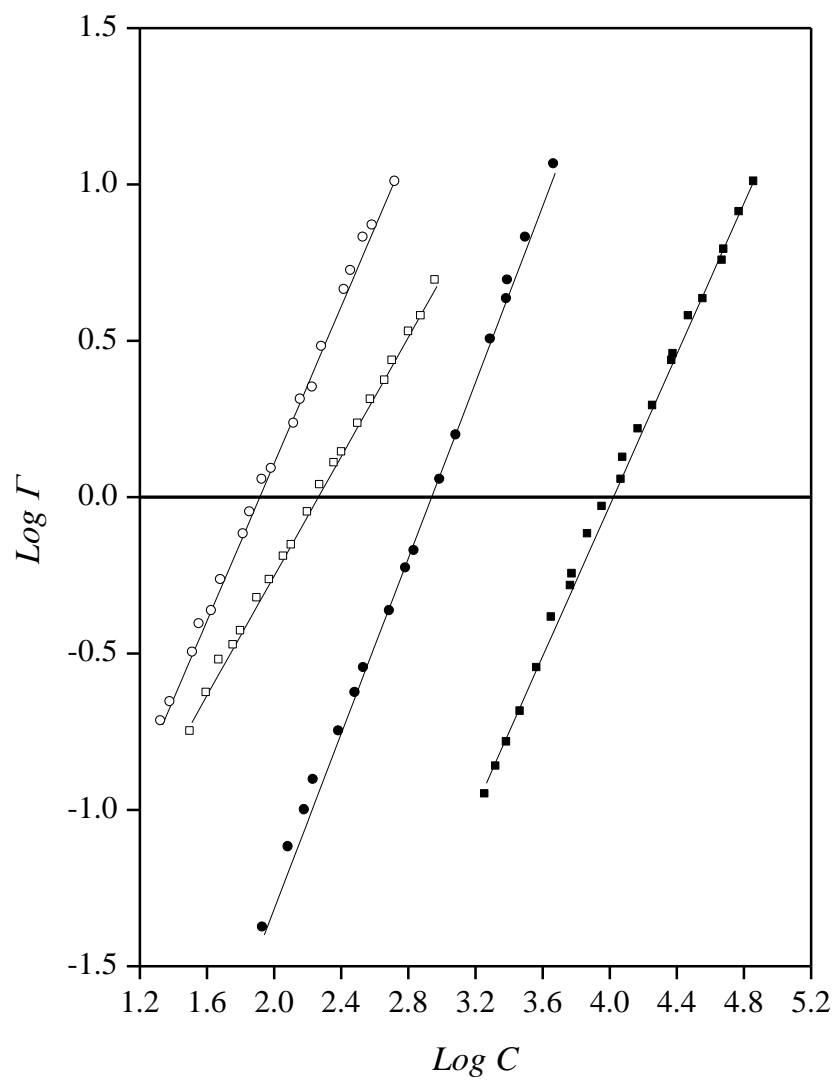

Fig. 3. Dose- response curves for compounds studied for Vibrio fischeri: acid, methyl levulinate, $\square$ ethyl levulinate, O butyl levulinate. 


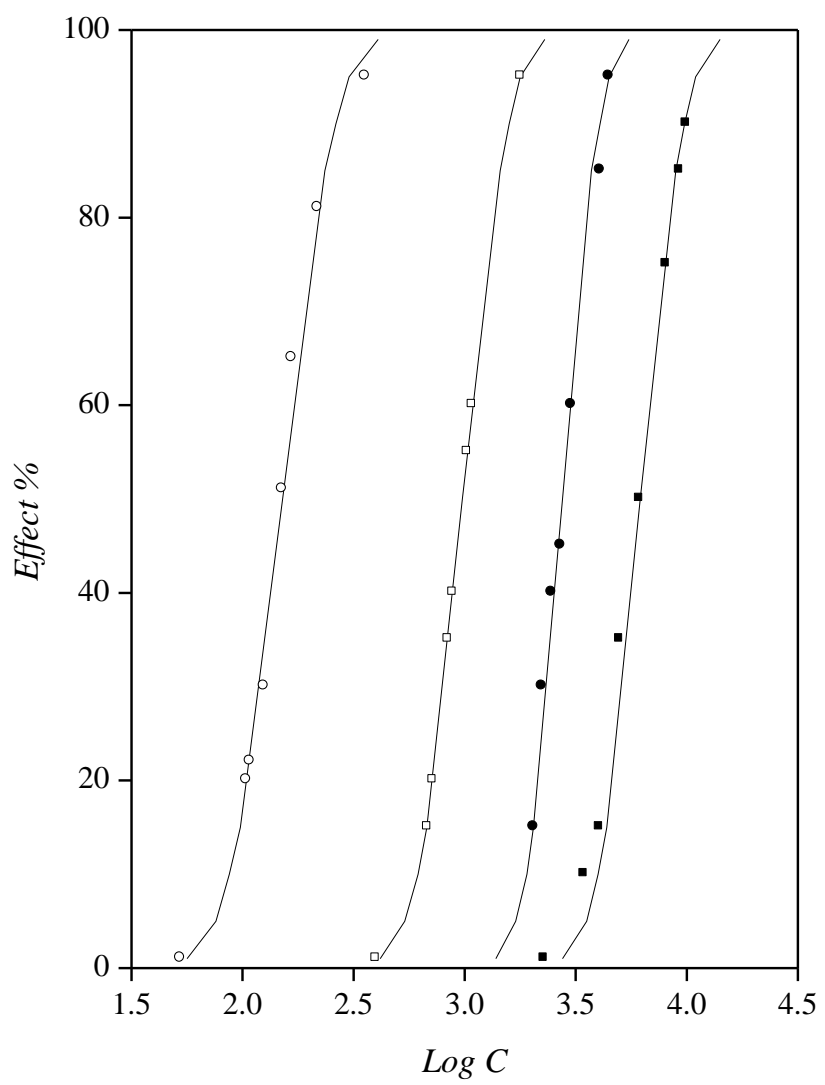

Fig. 4. Dose- response curves for compounds studied for Daphnia magna: $\mathbf{\square}$ levulinic acid, methyl levulinate, $\square$ ethyl levulinate, O butyl levulinate. 


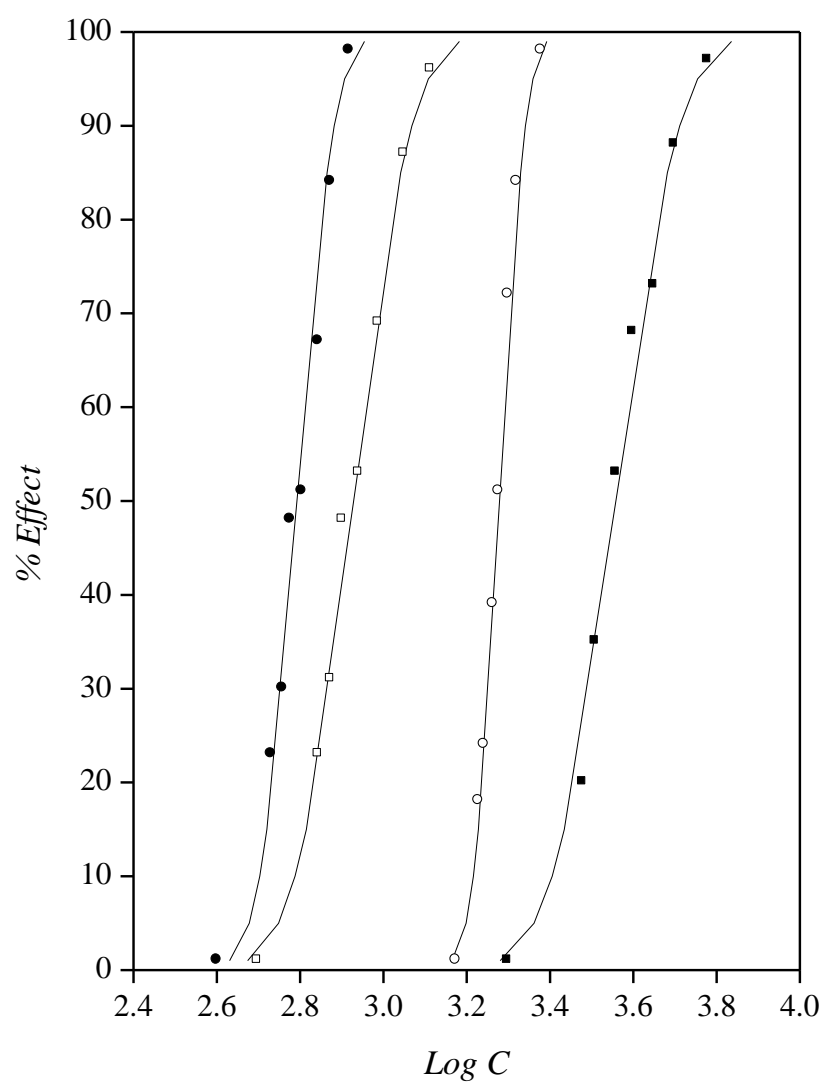

Fig. 5. Dose- response curves for compounds studied for Eisenia foetida: $\mathbf{\square}$ levulinic acid, methyl levulinate, $\square$ ethyl levulinate, O butyl levulinate 

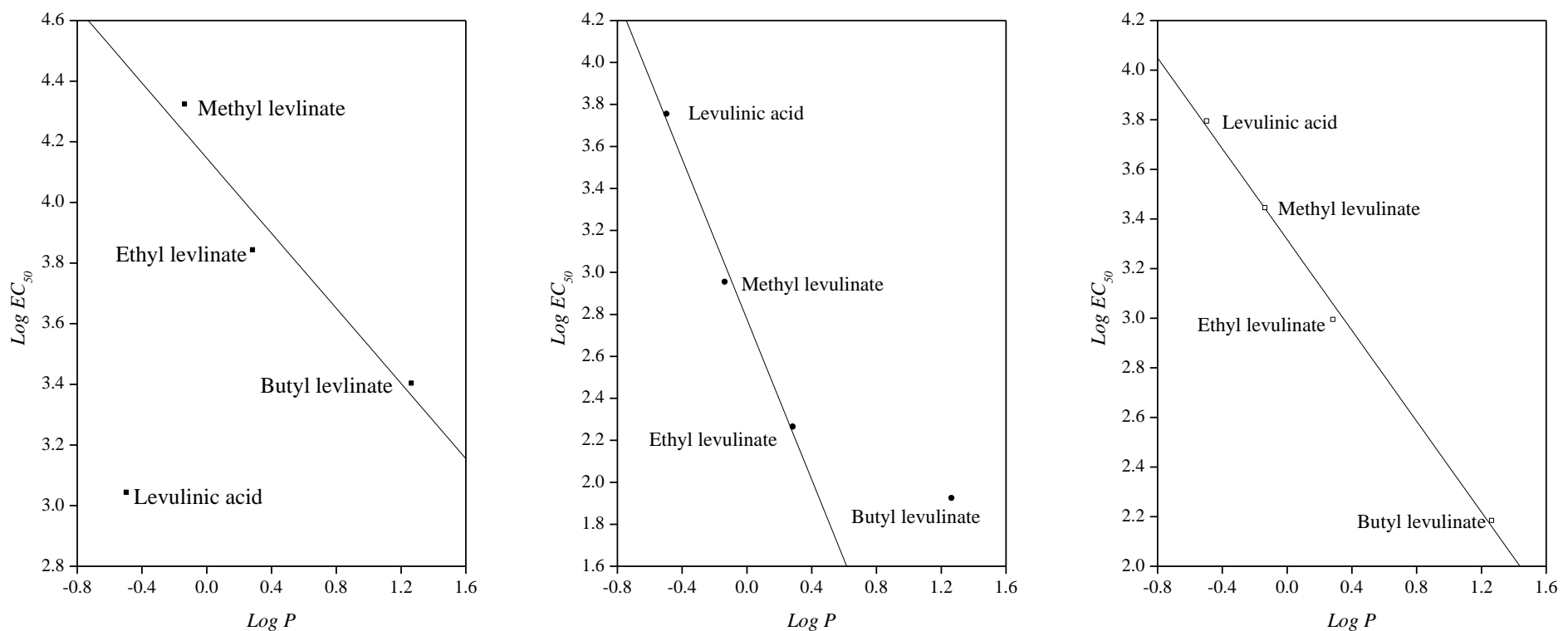

Fig. 6. Plots of acute $\left(\log \mathrm{EC}_{50}\right)$ toxicity for Chlamydomonas reinhardtii, Vibrio fischeri and Daphnia magna against the logarithm of the octanol-water partition coefficients $(\log P)$ : $\square$ Chlamydomonas reinhardtii, $\bullet$ Vibrio fischeri, $\square$ Daphnia magna.Position of LA in the first plot is mostly due to its high acidity. 
